\title{
Metalloproteases and Guidance of Retinal Axons in the Developing Visual System
}

\author{
Christine A. Webber, ${ }^{1 *}$ Jennifer C. Hocking, ${ }^{1 *}$ Voon W. Yong, ${ }^{2}$ Carrie L. Stange, ${ }^{1}$ and Sarah McFarlane ${ }^{1}$ \\ ${ }^{1}$ Genes and Development Research Group and 2Neuroscience Research Group, University of Calgary, Calgary, Alberta, \\ Canada, T2N 4N1
}

Axonal growth cones read cues in their environment that guide them to their target. Metalloproteases have been implicated in vitro in modulating the interaction of these cues with receptors in the growth cone. To determine whether metalloprotease function is important in the guidance of vertebrate axons in vivo, we applied hydroxamate-based metalloprotease inhibitors to Xenopus retinal ganglion cell (RGC) axons as they extended through the optic tract. In the presence of two different inhibitors, 0.5-20 $\mu \mathrm{M} \quad N-[(2 R)-2$ (hydroxamideocarbonylmethyl)-4methylpantanoyl]-L-tryptophan methylamide and batimastat, RGC axons made similar dose-dependent guidance errors. Most axons failed to make the expected caudal turn in the diencephalon and continued straight, growing aberrantly to-

The growth cone, a motile structure found at the tip of developing axons, reads cues in its environment to extend and reach its target. The presentation and transduction of these cues depend on additional molecules both intrinsic and extrinsic to the growth cone. In particular, metalloproteases have been implicated recently in vitro in modulating the interaction of guidance cues with their receptors (Zuo et al., 1998; Galko and Tessier-Lavigne, 2000; Hattori et al., 2000).

Metalloproteases are zinc-dependent proteolytic enzymes that include the matrix metalloprotease (MMP) and the A disintegrin and metalloprotease (ADAM) families. The former contains at least 26 members and is implicated in remodeling the extracellular matrix in diverse biological processes and in several pathologies of the CNS (Yong et al., 2001). Unlike most MMP family members, the majority of ADAM proteins are transmembrane. The ADAMs, of which there are at least 30, are unique in that they contain a cell-adhesion domain in addition to their proteolytic domain (Schlondorff and Blobel, 1999).

Both MMP and ADAM family members are expressed in the developing CNS (Vaillant et al., 1999; Yong et al., 2001). Their importance during key developmental processes such as neuro-

\footnotetext{
Received April 18, 2002; revised June 28, 2002; accepted July 9, 2002.

This work was supported by an operating grant from the Canadian Institutes of Health Research (CIHR). C.A.W. is supported by the Alberta Heritage Foundation for Medical Research (AHFMR), J.C.H. is supported by the National Sciences and Engineering Council of Canada, V.W.Y. is a CIHR scientist and an AHFMR senior scholar, and S.M. is a CIHR and AHFMR scholar. We thank Dr. C. Logan for her helpful comments on this manuscript and Shane Ferguson and Yuan Yuan Chen for excellent technical assistance.

*C.A.W. and J.C.H. contributed equally to this work.

Correspondence should be addressed to Dr. S. McFarlane, Genes and Development Research Group, University of Calgary, HSC Room 2207, 3330 Hospital Drive, Northwest, Calgary, Alberta, Canada, T2N 4N1. E-mail: smcfarla@ucalgary.ca. Copyright () 2002 Society for Neuroscience $\quad 0270-6474 / 02 / 228091-10 \$ 15.00 / 0$
}

ward and across the dorsal midline. As a result, few RGC axons innervated their midbrain target, the optic tectum. Similarly, if the inhibitors were applied after the axons made the turn, many failed to grow into the optic tectum and instead turned to grow along its anterior border. Interestingly, in many instances pathfinding defects were observed in the absence of problems with axon extension, although outgrowth was impaired at the higher doses of the inhibitors. These data provide compelling in vivo evidence that metalloproteases are important for both axon guidance and extension in the developing visual system.

Key words: growth cone; Xenopus; retinal ganglion cell; axon guidance; metalloprotease inhibitors; ADAM genesis, myelination, neuronal migration, and axon guidance is just starting to be elucidated (Yong et al., 2001). Early studies suggested a role for metalloproteases in axon elongation (Pittman, 1985; Machida et al., 1989; Sheffield et al., 1994). More recent tissue culture data suggest that metalloproteases regulate the signaling downstream of axon guidance cues through the cleavage of the ectodomains of several known guidance cues and receptors (Galko and Tessier-Lavigne, 2000; Hattori et al., 2000). Together, these in vitro data suggest that metalloproteases play roles in directing the trajectories of developing axons; however, in vivo evidence has been lacking.

To investigate whether metalloproteases regulate axon guidance in vivo, we concentrated on the growth and guidance of retinal ganglion cell (RGC) axons in the developing visual system of the frog Xenopus laevis. The Xenopus visual system has been well characterized (Chien and Harris, 1994), and the role of candidate molecules in the guidance of axons can be readily tested in vivo using an exposed brain preparation (Chien et al., 1993; McFarlane and Pollock, 2000). Several metalloproteases have been cloned in Xenopus; these include members of both the MMP and ADAM families (Alfandari et al., 1997; Piccolo et al., 1997; Yang et al., 1997; Cai et al., 1998; Goodman et al., 1998; Carinato et al., 2000). Many of these are expressed in the developing Xenopus embryo. Indeed, ADAM13 has been implicated recently in the migration of Xenopus cranial neural crest cells (Alfandari et al., 2001).

In this study, we have used hydroxamate-based inhibitors to modulate the activity of metalloproteases in vivo as Xenopus RGC axons extend through the brain to their main midbrain target, the optic tectum. We find that severe disruption of axon guidance occurs as a result. Axon extension was also impaired but was less sensitive to metalloprotease inhibition. 


\section{MATERIALS AND METHODS}

Animals. Eggs were obtained from adult female $X$. laevis stimulated with human chorionic gonadotropin (Intervet Canada Ltd., Whitby, Ontario, Canada), and fertilized in vitro (Sive et al., 2000). Embryos were raised in $0.1 \times$ Marc's modified Ringer's solution (Sive et al., 2000) at $20-25^{\circ} \mathrm{C}$ and staged according to the Nieuwkoop and Faber (1994) staging tables.

Bathing media and metalloprotease blockers. The exposed brain preparation was performed as described previously (Chien et al., 1993). Briefly, embryos were anesthetized in modified Barth's solution (MBS) supplemented with $0.4 \mathrm{mg} / \mathrm{ml}$ tricaine (ethyl 3-aminobenzoate methanesulfonic acid; Aldrich, Milwaukee, WI), $50 \mathrm{mg} / \mathrm{ml}$ gentamicin sulfate (Sigma, Oakville, Ontario, Canada), and $10 \mathrm{mg} / \mathrm{ml}$ Phenol Red (Sigma). The embryos were pinned in a Sylgard dish (Dow Corning, Midland, $\mathrm{MI}$ ), and the skin and dura covering the left brain was removed. This procedure exposes the entire anterior brain on one side, reaching as far caudal as the posterior optic tectum. After surgery, the embryos were randomly divided into two groups and were allowed to develop in either experimental or control solutions for another 18-24 hr until they reached stage 40 . To block metalloproteases, hydroxamate-based inhibitors were added to the control MBS ( $\mathrm{pH} 7.4)$ solution: 0.5-20 $\mu \mathrm{M} \mathrm{N} N-[(2 R)-2-$ (hydroxamideocarbonylmethyl)-4-methylpantanoyl]-L-tryptophan methylamide (GM6001) (Calbiochem, San Diego, CA) and 0.1-5 $\mu$ M batimastat (BB-94; British Biotech, Oxford, UK). In a separate series of experiments, the specificity of GM6001 was tested using $N$-t-butoxycarbonyl-L-leucylL-tryptophan methylamide (Calbiochem), a closely related compound, as a negative control.

Visualization of the optic projection. The optic projection was visualized by anterogradely labeling RGC axons using horseradish peroxidase (HRP, type VI; Sigma) as described previously. Briefly, the lens of the right eye was surgically removed and HRP dissolved in $1 \%$ lysolecithin was placed in the eye cavity (Cornel and Holt, 1992). Embryos were fixed overnight in $4 \%$ paraformaldehyde in $0.1 \mathrm{M}$ sodium phosphate buffer, $\mathrm{pH}$ 7.4. Dissected brains were washed in PBS, reacted with diaminobenzidine (Sigma), dehydrated through a graded series of alcohols, and cleared in 2:1 benzyl benzoate:benzyl alcohol. Whole-mount brains were mounted in Permount (Fisher Scientific Ltd., Nepean, Ontario, Canada) under a coverslip supported by two plastic reinforcement rings (Avery Office Products Canada, Bowmanville, Ontario, Canada). The outlines of brains and optic projections were drawn using a camera lucida attachment on a Zeiss (Thornwood, NY) microscope. Digital images of preparations were taken using a Spot II camera (Diagnostic Instruments, Sterling Heights, MI) and processed for brightness and contrast with Adobe Photoshop 4.0 software (Adobe Systems, San Jose, CA).

Quantification of optic projection length and turning angle. The effects of metalloprotease inhibitors were quantified by measuring the length and turning angle of optic projections in control and treated brains. Camera lucida representations of mounted brains were scanned with an Astra 1200s flatbed scanner (Umax, Freemont, CA) to provide digital images. Samples were used only if they were mounted without significant rolling and had well filled optic projections. Analysis was performed using the public domain NIH Image program. Brains were normalized using macro programs described previously (Chien et al., 1993) by rotating and scaling them to a line drawn between the anterior optic chiasm and the midbrain-hindbrain isthmus. This line was matched to a standard reference line, artificially defined as 1 brain reference unit (b.r.u.); 1 b.r.u. is $\sim 620 \mu \mathrm{m}$ in an unfixed brain (Chien et al., 1993). The optic chiasm and the isthmus were chosen as easily identified and reliable morphological markers in the Xenopus brain. The reference line was divided into 0.1 intervals through which concentric circles were drawn. The optic-tract length was measured from the optic chiasm to the end of the optic projection containing at least $1 \%$ of RGC axons ( $>10$ axons). The angle through which the optic projection makes a turn in the mid-diencephalon was also measured (see Fig. $3 A$ ). A line was drawn at a $60^{\circ}$ angle to the reference line between the optic chiasm and the midbrain-hindbrain isthmus, bisecting the optic tract at the level of the turn made in the mid-diencephalon. The angle between this line and a line drawn through the middle of the projection that runs dorsal to this line was measured. Unless otherwise stated, samples were compared statistically using an unpaired ANOVA, followed by a Student-Newmann-Keuls multiple comparison post hoc test (Instat; GraphPad Software Inc., San Diego, CA).

Retinal cell cultures. Eye primordia were dissected from stage 24 embryos and cultured as described previously (Harris and Messersmith, 1992). Briefly, dissociated cells or entire eyes were plated onto polyornithine/laminin-coated coverslips in $35 \mathrm{~mm}$ Petri dishes containing culture media. Culture media consisted of $60 \%$ L15-glutamine (Invitrogen, San Diego, CA) supplemented with $5 \%$ fetal bovine serum (Invitrogen), penicillin-streptomycin (Invitrogen), and 1\% embryo extract. Explant cultures were used for immunohistochemistry and analysis of growth cone morphology.

Immunocytochemistry. Frozen transverse sections $(12 \mu \mathrm{m})$ were cut through the eyes and brain of exposed embryos. The sections were immunolabeled with mouse monoclonal antibodies against ADAM10 (1:200; Chemicon, Temecula, CA), Islet-1 (394D5, 1:100; Developmental Studies Hybridoma Bank, University of Iowa, Iowa City, IA), neural cell adhesion molecule (NCAM) (6F11, 1:10; Developmental Studies Hybridoma Bank), $\beta$-tubulin (1:1000; Sigma), 3CB2 (1:10; Developmental Studies Hybridoma Bank), neurofilament (RMO270, 1:400; Zymed, San Francisco, CA), Zn-12 (1:10; Developmental Studies Hybridoma Bank), and Deleted in Colorectal Cancer (DCC, 1:20; Oncogene, Boston, MA). A rabbit polyclonal antibody that recognizes GABA (1:3000; Sigma) was also used. Rhodamine-conjugated secondaries (Jackson ImmunoResearch, West Grove, PA) were used at a dilution of 1:500. In a separate series of experiments, $12 \mu \mathrm{m}$ cryostat sections through the midbrain and forebrain of control embryos or those treated with $5 \mu \mathrm{M}$ GM6001 were processed for DCC immunocytochemistry. For each sample, the intensity of labeling in the neuropil of at least three adjacent sections was measured using NIH Image. The background staining intensity of an unlabeled portion of the section was subtracted from the neuropil measurement.

Western blot analysis. Stage 42 Xenopus head tissue was homogenized in $120 \mathrm{~mm}$ Tris, pH 6.8, $10 \mathrm{~mm}$ EDTA, $0.1 \mathrm{mg} / \mathrm{ml} \mathrm{RNase} \mathrm{A} \mathrm{(Amersham}$ Biosciences, Baie d'Urfe, Quebec, Canada), and $1 \mathrm{~mm}$ phenylmethylsulfonyl fluoride (Sigma). The homogenate was then centrifuged at $16,000 \times g\left(4^{\circ} \mathrm{C}\right)$ for $10 \mathrm{~min}$. The supernatant was removed and diluted appropriately in SDS sample buffer (SDS, bromophenol blue; LKB, Bromma, Sweden), Tris-HCl, and glycerol (BDH Chemicals, Toronto, Canada) containing DTT (Sigma). Samples were boiled for $5 \mathrm{~min}$ and run on a $10 \%$ SDS-polyacrylamide resolving gel. After electrophoresis, proteins were electrolytically transferred to polyvinylidene difluoride membranes (Bio-Rad, Hercules, CA). The membranes were blocked in Tris-buffered saline (TBS) containing $0.05 \%$ Tween $20,1 \%$ bovine serum albumin (Sigma), and $1 \%$ dry milk powder and incubated overnight at $4^{\circ} \mathrm{C}$ in fresh blocking solution containing ADAM10 primary antibody (1:1000 dilution). The membranes were rinsed in TBS with $0.2 \%$ Tween 20 and incubated for $1 \mathrm{hr}$ in a peroxidase-conjugated mouse anti-rabbit secondary antibody (Jackson ImmunoResearch). Protein bands were detected with ECL reagents per the manufacturer's instructions (Amersham Biosciences).

\section{RESULTS}

\section{RGC axon guidance defects occur in the presence of a metalloprotease inhibitor}

To determine whether metalloproteases are important in the guidance of axons in vivo, we applied a hydroxamate-based metalloprotease blocker to the developing optic projection using a previously described exposed brain preparation (Chien et al., 1993; McFarlane et al., 1995). The skin and dura are removed from one side of the brain of a stage 33/34 embryo, as the first axons from the contralateral eye cross the optic chiasm to reach the diencephalon. Optic axons grow close to the pial surface and are therefore exposed to the metalloprotease blocker over the entire course of their growth through the diencephalon toward the optic tectum. Axons are anterogradely labeled with HRP at stage 40 , the stage at which the majority will have reached the optic tectum in control brains (Fig. $1 A$ ). Using this preparation, it is possible to determine whether a drug known to inhibit metalloprotease function affects the extension, pathfinding, and/or target recognition of developing RGC axons.

The broad-spectrum metalloprotease inhibitor GM6001 blocks the proteolytic activity of both MMP and ADAM family members. GM6001 application, at concentrations used previously in in vitro studies (Alexander et al., 2001; Karsdal et al., 2001), had a dose-dependent effect on both the extension and the guidance of the optic tract in vivo. At a low $0.5 \mu \mathrm{M}$ GM6001 dose, the optic 

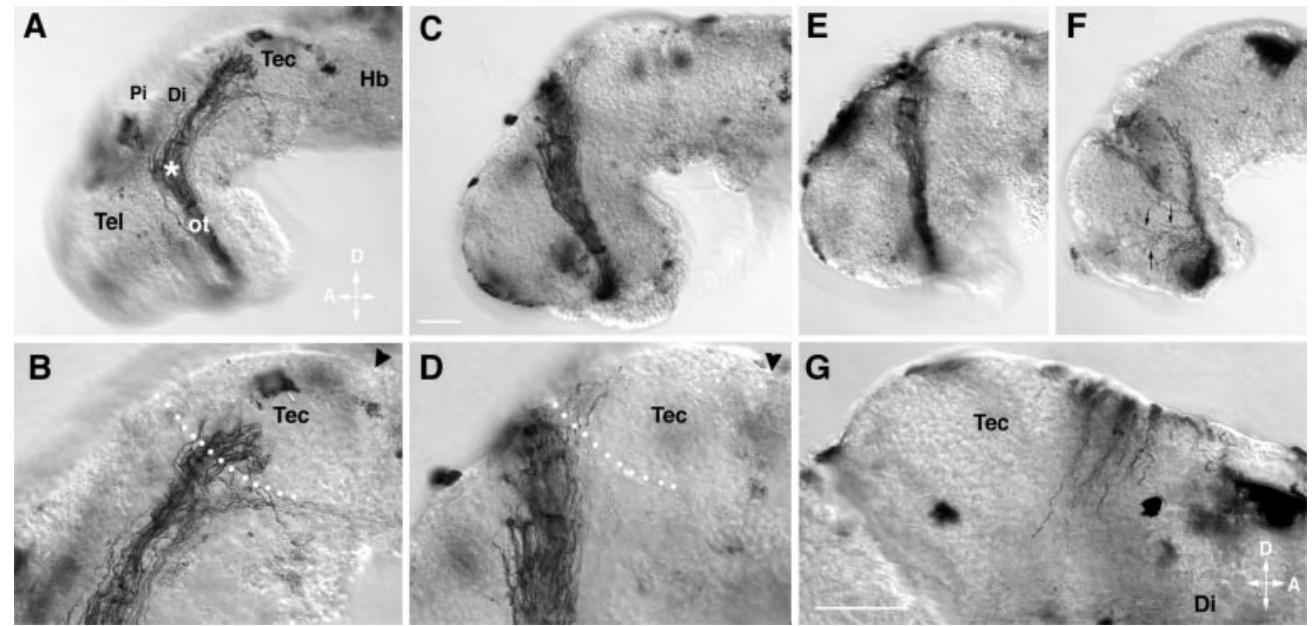

Figure 1. RGC axons make improper guidance decisions in the presence of the metalloprotease inhibitor GM6001. $A-G$, Representative examples of stage 40 whole-mount brain preparations showing the HRP-labeled optic projection in a control brain $(A, B)$ and when GM6001 was applied to the exposed brain $(C-G) . B$ and $D$ are higher-power views of $A$ and $C$, respectively. $C, D, \mathrm{~A} 1$ $\mu \mathrm{M}$ concentration of GM6001. E, A 10 $\mu \mathrm{M}$ concentration of GM6001. $F$, A 20 $\mu \mathrm{M}$ concentration of GM6001. $G$, Axons cross over the dorsal midline into the contralateral brain of a $1 \mu \mathrm{M}$ GM6001treated brain. Tec, Tectum; $P i$, pineal gland; $\mathrm{Di}$, diencephalon; $\mathrm{Tel}$, telencephalon; ot, optic tract; $H b$, hindbrain; $D$, dorsal; $A$, anterior. Arrowheads mark the midbrain-hindbrain isthmus; the asterisk marks the caudal turn of the optic projection in the mid-diencephalon, and arrows in $F$ show axons growing aberrantly in the telencephalon. White dots show the approximate anterior border of the optic tectum. Scale bars: $C, 50 \mu \mathrm{m} ; A, C, 65 \mu \mathrm{m}$ for $E$ and $F$; and $G, 50 \mu \mathrm{m}$ for $B, D$, and $G$.
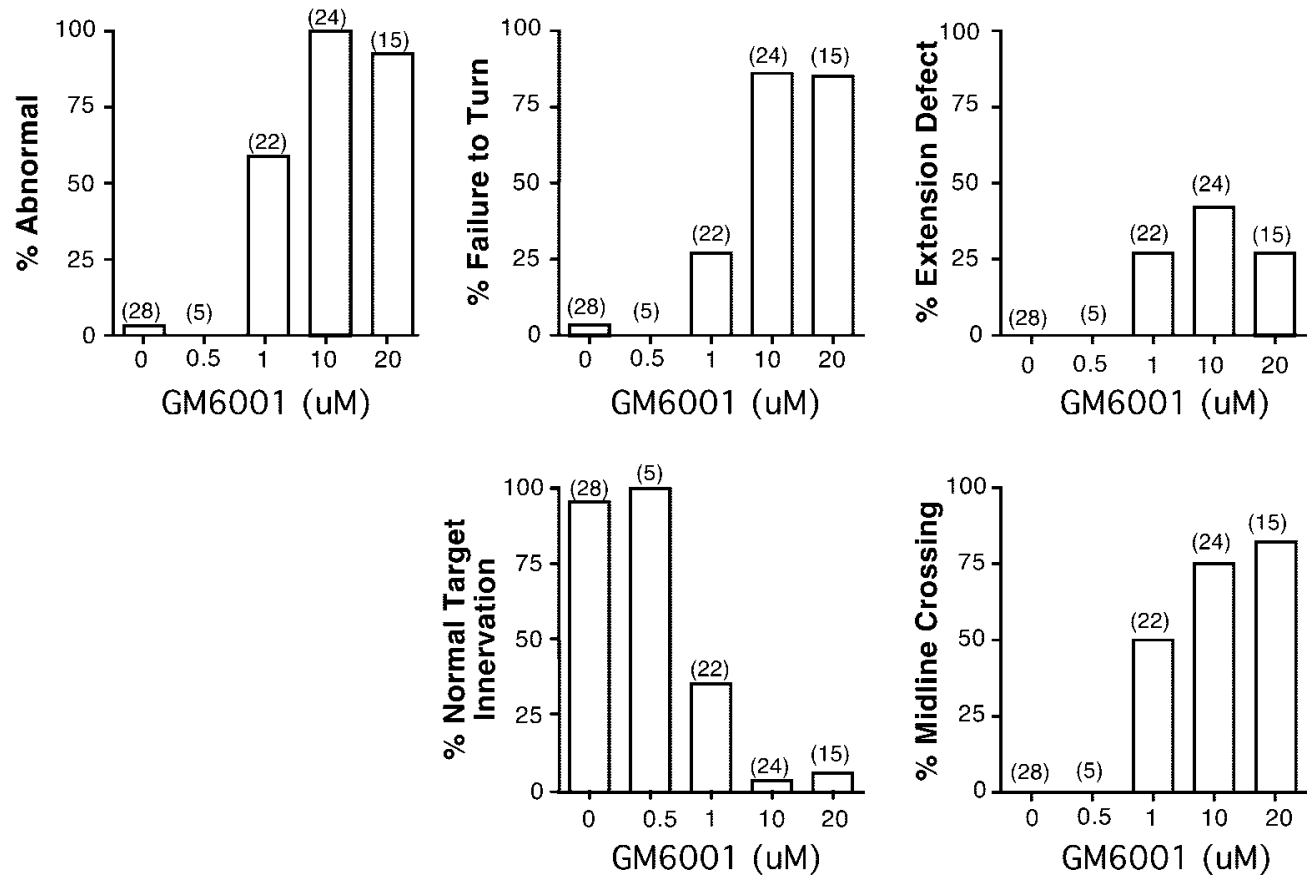

Figure 2. Defects in RGC axon pathfinding and target recognition caused by the application of GM6001. A qualitative description of the different defects in axon behavior observed in optic projections treated with different doses of GM6001 is given. Numbers in parentheses represent the number of embryos. \% $A b$ normal is the percentage of embryos with some defect in the optic projection; \% Failure to Turn refers to optic projections in which the majority of axons show a guidance defect in the mid-diencephalon, where RGC axons normally make a caudal turn toward the optic tectum; \% Extension Defect refers to a shortened optic projection; \% Normal Target Innervation means that the majority of RGC axons enter the optic tectum; \% Midline Crossing refers to axons that extend aberrantly across the dorsal midline into the contralateral brain. projections resembled those of control embryos (Fig. 2). However, at 1 and $10 \mu \mathrm{M}$ GM6001, 59\% (13 of 22) and 100\% (24 of 24) of the optic projections, respectively, showed some abnormality, compared with only $4 \%$ ( 1 of 28 ) in controls (Figs. $1 C-G, 2)$. In $27 \%$ of the brains treated with $1 \mu \mathrm{M}$ GM6001, the majority of RGC axons failed to make the turn in the mid-diencephalon (Fig. $1 C-E)$ and instead continued growing straight, often crossing the dorsal midline (Figs. $1 G, 2$ ). At higher doses, $85 \%$ of the optic projections failed to turn (Fig. 2). In addition, some axons showed aberrant growth into the telencephalon (Fig. $1 F$ ) and/or their extension was impaired (Figs. 1F,2).

Defects in innervation of the optic tectum were also observed in GM6001-treated embryos. In control embryos, axons grew into the optic tectum in a directed manner and then branched and arborized in the anterior tectum (Figs. $1 A, B, 2)$. In contrast, the optic tectum was not innervated in $64.6 \%(n=22)$ and $95.8 \%$ $(n=24)$ of 1 and $10 \mu \mathrm{M}$ GM6001-treated optic projections, respectively. In cases in which RGC axons turned in the middiencephalon and reached the border of the optic tectum, the majority of axons ignored the target entirely and instead grew along its anterior border in 43\% (6 of 14) and 89\% ( 8 of 9) of 1 and $10 \mu \mathrm{M}$ GM6001-treated optic projections, respectively (Fig. 1D).

To quantify both the extension and the pathfinding defects observed with the GM6001 inhibitor, the angle through which axons turn at the mid-diencephalon and the length of the optic projection were measured (Fig. 3). A dose-dependent effect on both parameters was observed. Interestingly, these data suggest that blocking metalloprotease activity had a significant effect on axon pathfinding at concentrations at which axon outgrowth was impaired only moderately. Indeed, there were many examples in which axons clearly failed to turn in the mid-diencephalon but were not obviously impaired in their outgrowth (Fig. $1 C-E$ ).

To test the specificity of the effect of GM6001, we used a closely related L-tryptophan methylamide compound that does not in- 

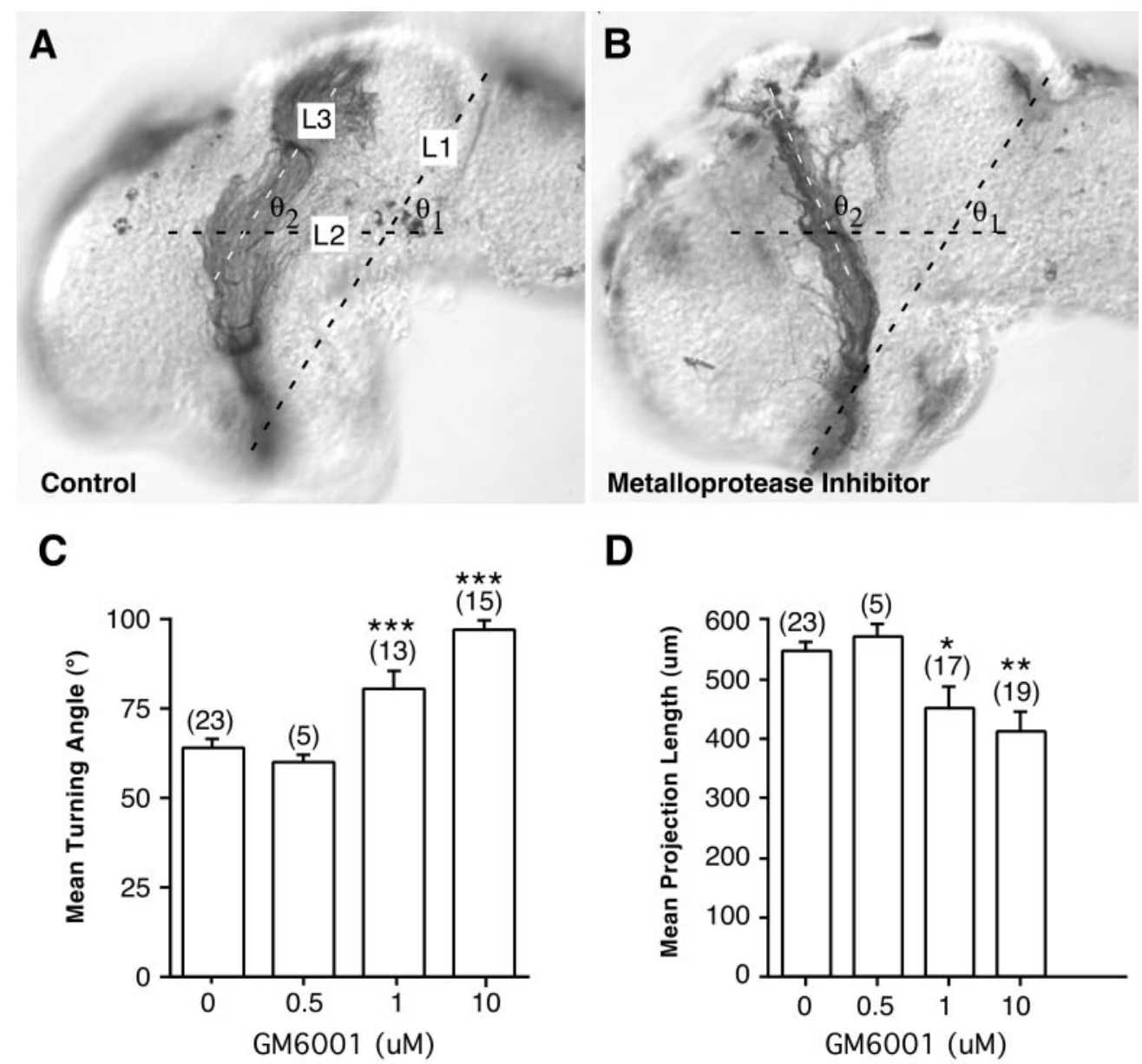

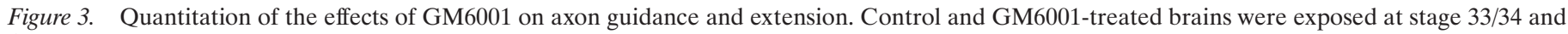

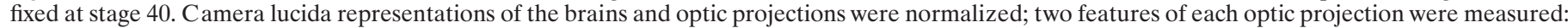

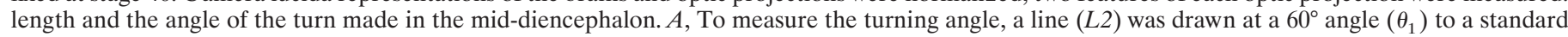

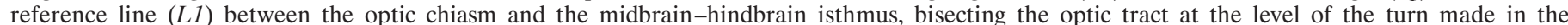

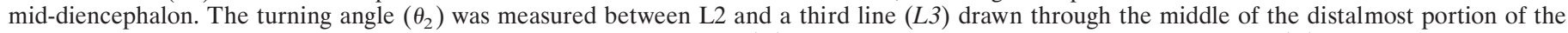

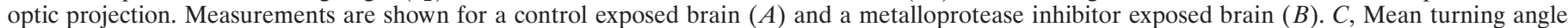

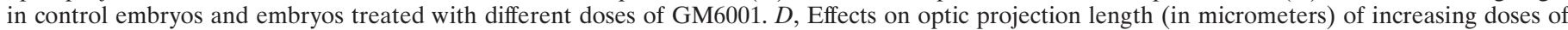

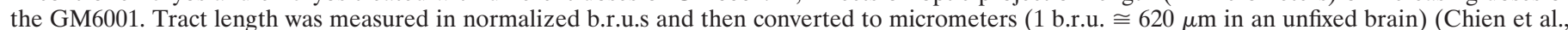

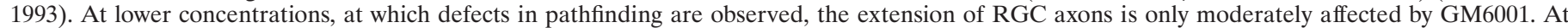

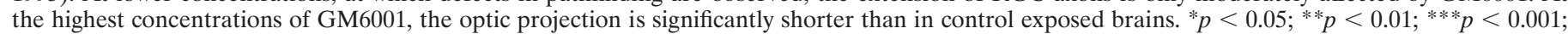
ANOVA, Student-Newmann-Keuls post hoc test. The numbers of embryos are shown in parentheses, and error bars are SEM.

hibit metalloprotease activity and serves as a negative control (Galko and Tessier-Lavigne, 2000). The GM6001 negative control had no obvious effect on the optic projection compared with control (Fig. $4 A, B$ ). Indeed, the average axon length and turning angle were not significantly different from those of control-treated projections (Fig. 4C,D).

\section{The metalloprotease inhibitor BB-94 also causes defects in axon extension and guidance}

To test the specificity of the GM6001 effect for metalloproteases, we treated the optic projection with a second metalloprotease inhibitor, BB-94 (Brown, 1998). BB-94 is a broad-spectrum metalloprotease inhibitor that blocks members of both the MMP and ADAM families. BB-94 had effects similar to those of GM6001 on RGC axon pathfinding, target recognition, and axon extension (Figs. 5, 6). Defects in axon guidance were observed with BB-94 concentrations comparable with those used previously in cell culture studies (Parvathy et al., 1998; Nath et al., 2001). At a concentration of $0.1 \mu \mathrm{M}, \mathrm{BB}-94$ had little or no effect on the optic projection (Figs. $5 A, 6$ ). In contrast, with doses of $\geq 0.5 \mu \mathrm{M}$, defects in axon extension and in the ability of RGC axons to make the turn in the mid-diencephalon were observed (Figs. $5 B-D$, $6 A$ ). The effect of BB-94 on these two parameters was quantified and is shown in Figure $6 B, C$. As with GM6001, significant defects in axon turning were observed at lower BB-94 concentrations than was required to inhibit axon extension.

\section{Inhibitors may act on metalloproteases expressed by cells lining the optic tract or in RGC growth cones}

GM6001 and BB-94 could act on metalloproteases expressed by neuroepithelial cells lining the optic tract, and/or RGC growth cones themselves. Consistent with this, metalloproteases have been found previously in both the developing rodent optic nerve and the RGC layer (Canete Soler et al., 1995; Agapova et al., 2001). In Xenopus, MMPs and ADAMs are present in the developing eye primordium and/or forebrain (Alfandari et al., 1997; Pan and Rubin, 1997; Cai et al., 1998; Damjanovski et al., 2000). Notably, mutants of the Drosophila ADAM10 ortholog kuzbanian 

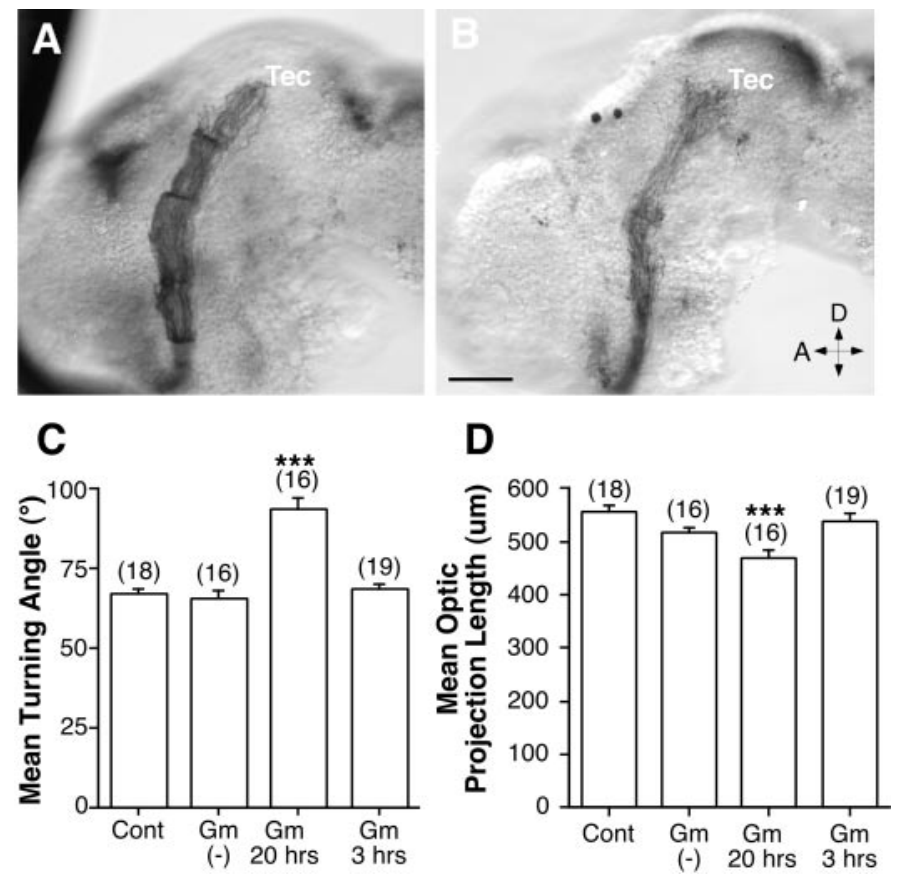

Figure 4. A compound related to GM6001 that does not inhibit metalloproteases fails to influence formation of the optic projection. An L-tryptophan methylamide compound, GM6001 negative control, was applied to the developing optic projection using the exposed brain preparation. $A, B$, HRP-labeled projections in stage 40 brains exposed at stage $33 / 34$ to control $(A)$ and $5 \mu \mathrm{M}$ GM6001 negative control solutions $(B)$. Tec, Tectum; $D$, dorsal; $A$, anterior. $C, D$, Graphs of the mean turning angle $(C)$ and mean normalized optic projection length $(D)$ in brains exposed to $0.2 \%$ DMSO (Cont), $5 \mu \mathrm{M}$ GM6001 negative control [Gm(-)], or $5 \mu \mathrm{M}$ GM6001 $(\mathrm{Gm})$ for 3 or $20 \mathrm{hr}$. The numbers of embryos are shown in parentheses, and error bars are SEM. ${ }^{* *} p<0.001$; ANOVA, StudentNewmann-Keuls post hoc test). Scale bar: (in $B) A, B, 50 \mu \mathrm{m}$.

(kuz) exhibit axon stalling defects (Fambrough et al., 1996), and Xenopus kuz mRNA is expressed at early tailbud stages in the forebrain and the eye (Pan and Rubin, 1997). However, it is unknown whether Xenopus KUZ protein (XKUZ) continues to be expressed as the first RGC axons reach the turn in the mid-diencephalon, the site where errors are made in the presence of metalloprotease inhibitors. Thus, we performed immunocytochemical labeling of transverse frozen sections through the brain and retina of stage 35/36 embryos with a rabbit polyclonal antibody raised against a human ADAM10 peptide. The specificity of the antibody for XKUZ was confirmed by Western blot analysis (Fig. 7A). Similar to what is observed in the rat cerebellum, a band of $\sim 75 \mathrm{kDa}$ was observed in Xenopus. Figure $7 B, C$ shows that XKUZ-like immunoreactivity is expressed both by RGC somata and by cells lining the optic tract, but is not present in the optic nerve or the brain neuropil.

Nonetheless, given that chick RGC axons have gelatinase activity (Sheffield and Graff, 1991), it is likely that Xenopus RGC axons and growth cones also express metalloproteases. To test the possibility that the metalloprotease inhibitors could be acting on RGC growth cones directly, we examined whether GM6001 affected retinal growth cone morphology in culture, where there is no neuroepithelial substrate on which the metalloprotease inhibitors could act. We treated 1-d-old stage 24 retinal explant cultures with $5 \mu \mathrm{M}$ GM6001 for $24 \mathrm{hr}$ and assayed RGC growth cone morphology. Importantly, RGCs are the only cells to send axons out of the eye explants. Neurite outgrowth from the GM6001-
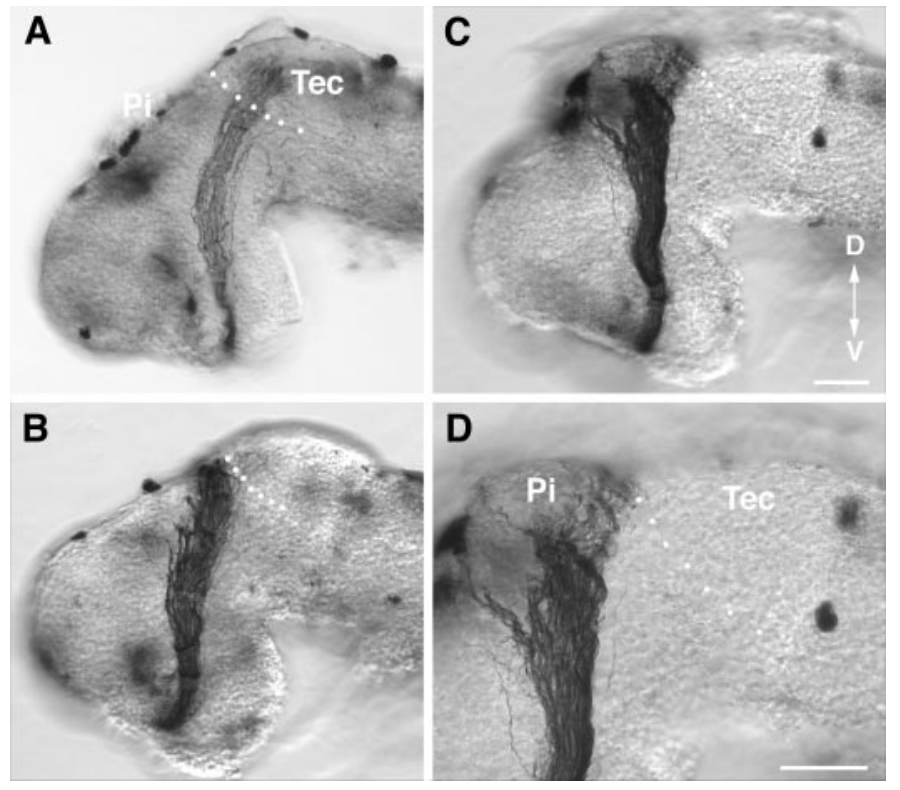

Figure 5. A second metalloprotease inhibitor, BB-94, has effects similar to those of GM6001 on RGC axon guidance and extension. $A-D$, HRPlabeled optic projections in stage 40 whole-mount brains exposed at stage $33 / 34$ to $0.1 \mu \mathrm{M}(A)$ and $1.0 \mu \mathrm{M}(B-D)$ BB-94. At the low dose of BB-94 $(A)$ the optic projection forms normally. At $1.0 \mu \mathrm{M}$, BB-94 RGC axons do not turn in the mid-diencephalon $(B, C)$ and fail to innervate the optic tectum $(D) . D$ is a higher-power view of $C$. The dotted white line shows the approximate anterior border of the optic tectum. Tec, Tectum; Pi, pineal gland; $D$, dorsal; $V$, ventral. Scale bars: $C$ (for $A-C$ ), $D, 50 \mu \mathrm{m}$.

treated explant cultures was similar to that seen in controls. Consistent with this observation, GM6001 had no obvious effect on the morphology of growth cones in culture (Fig. 8A,B). A collapsed morphology was seen in $34.0 \%(n=194)$ and $34.6 \%$ $(n=162)$ of growth cones in control and $5 \mu \mathrm{M}$ GM6001-treated cultures, respectively. Moreover, growth cones had similar numbers of filopodia $(5.25 \pm 0.4, n=6$ cultures in control; $5.18 \pm 0.3$, $n=5$ cultures in GM6001) in the two treatment conditions. These data indicate that in the absence of a neuroepithelial substrate, metalloprotease inhibition did not affect RGC growth cone morphology or neurite extension.

An alternative explanation for the defects we observed in axon guidance is that GM6001 grossly disrupted the patterning and/or morphology of the neuroepithelium through which the RGC axons extend. However, short $3 \mathrm{hr}$ applications of $5 \mu \mathrm{M}$ GM6001 did not impair RGC axon extension and/or guidance in vivo (Fig. $4 C, D)$. In addition, brains treated with a longer-term application of GM6001 for $24 \mathrm{hr}$ were apparently normal (Fig. 8). We performed immunolabeling of control and metalloprotease-treated brains with various neuroepithelial cell markers. These included antibodies that recognize: (1) general neuronal markers such as NCAM, Zn-12 (Fig. 8C,D) (Metcalfe et al., 1990), (2) $\beta$-tubulin (Fig. 8E), (3) Islet-1, a lim homeodomain protein that is expressed by ventrally positioned neurons in the forebrain (Fig. $8 F$ ) (Ericson et al., 1995), and (4) a population of GABA-expressing neurons found at the guidance decision point in the middiencephalon, where RGC axons make their caudal turn toward the optic tectum (Roberts et al., 1987; Ferguson and McFarlane, 2002) (Fig. 8G,H). No obvious difference in the intensity or pattern of marker expression was observed between the control and GM6001-treated brains. 
A
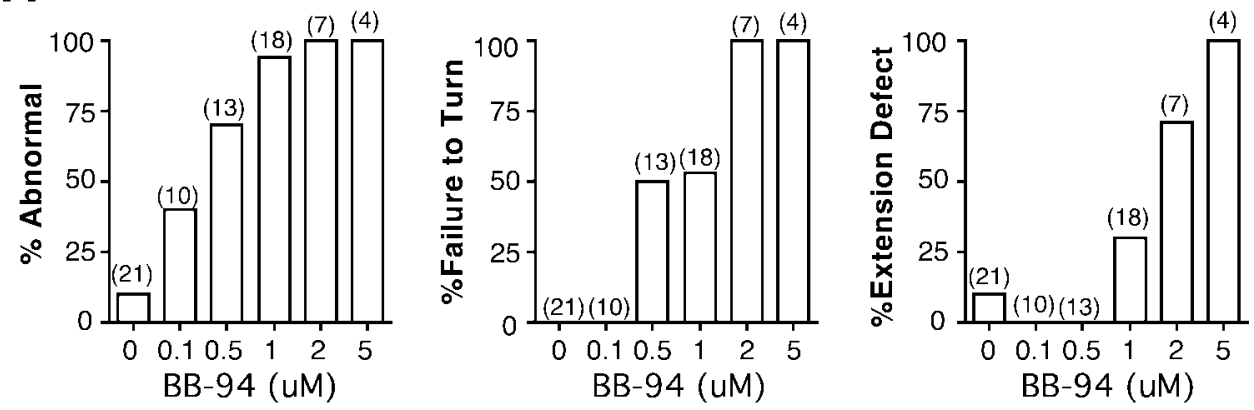

Figure 6. Defects in RGC axon pathfinding and target recognition caused by the application of BB-94. A, Qualitative description of the different defects in axon behavior observed in optic projections treated with BB-94. Numbers in parentheses represent the number of embryos. The description of the defects is the same as presented in the legend to Figure 2. B, C, Control and BB-94-treated brains were exposed at stage 33/34 and fixed at stage 40 . Measurements were made as described in the legend to Figure 3. $B$, Effect on mean turning angle of increasing doses of BB-94. $C$, Dose-response of the effects of BB-94 on optic tract length (in micrometers). At lower concentrations, at which defects in pathfinding are observed, the extension of RGC axons is unaffected by BB-94. At the highest concentrations of BB-94, the optic projection is significantly shorter than in control exposed brains. ${ }^{*} p<0.05$; ${ }^{*} p<<$ $0.01 ;{ }^{* *} p<0.001$; ANOVA, StudentNewmann-Keuls post hoc test. The numbers of embryos are shown in parentheses, and error bars are SEM.
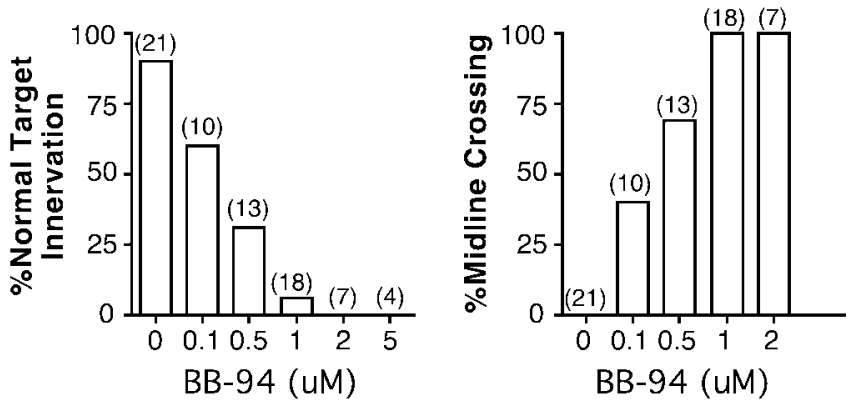

\section{Metalloproteases regulate the protein levels of the axon guidance receptor, DCC}

Previous culture studies have suggested that the ectodomain of the Netrin receptor, DCC, is cleaved by metalloproteases, rendering the receptor inactive (Galko and Tessier-Lavigne, 2000). In Xenopus, DCC is expressed both by RGC growth cones and by cells in the diencephalon through which the axons extend (de la Torre et al., 1997). To determine whether metalloprotease inhibitors could influence the cleavage of DCC, transverse frozen sections through the forebrain and midbrain of embryos exposed to either $5 \mu \mathrm{M}$ GM6001 or control solution were processed for immunocytochemistry with a mouse monoclonal antibody against DCC (de la Torre et al., 1997). The intensity of DCC immunolabeling of the neuropil on the treated side was measured (see Materials and Methods) and the GM6001-treated neuropil $[63.5 \pm 9(\mathrm{SEM}) ; n=6]$ was $63 \%$ brighter $(p<0.01$; paired, two-tailed $t$ test) than control $(41.4 \pm 14 ; n=6)$. These data suggest that metalloproteases function in the Xenopus diencephalon to cleave at least one guidance receptor.

\section{Metalloprotease inhibition results in target recognition errors by RGC axons}

When GM6001 was applied to RGC axons as they first entered the ventral diencephalon, few axons innervated the optic tectum.
However, it was unclear whether the target-recognition defect was secondary to the earlier guidance errors made by the RGC axons in the mid-diencephalon. To determine whether metalloprotease activity is important for normal target recognition, $5 \mu \mathrm{M}$ GM6001 was applied to the developing optic projection at stage $37 / 38$, just as the first axons reach the optic tectum. All control optic projections innervated the optic tectum normally (10 of 10), whereas in virtually all GM6001-treated brains a significant number of RGC axons failed to recognize their target and grew along its anterior border (10 of 11) (Fig. 9). Thus, RGC axons make two key guidance errors when metalloprotease activity is inhibited; they fail to make a caudal turn in the mid-diencephalon and they ignore their normal midbrain target.

\section{DISCUSSION}

Our data suggest that metalloprotease activity is required in vivo for RGC axons to make appropriate guidance decisions at critical choice points. When metalloproteases were inhibited pharmacologically in an in vivo preparation, most RGC axons extended appropriately. However, axons failed to make the correct guidance decisions. First, RGC axons grew straight in the middiencephalon, where they normally make a caudal turn toward their target, the optic tectum. Second, many axons that reached 

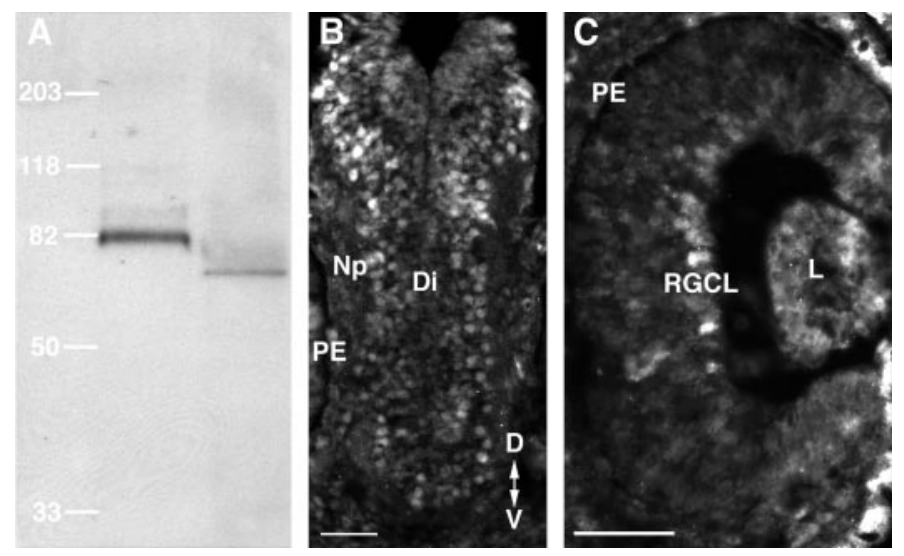

Figure 7. Xenopus Kuzbanian is expressed in the developing diencephalic brain neuroepithelium. $A$, Western blot of adult rat cerebellar (left) and stage 42 Xenopus head (right) tissue using a rabbit antibody developed against a human ADAM10 peptide. Molecular masses are indicated based on standards run at the same time as the sample tissue. A prominent protein band with an approximate molecular mass of $82 \mathrm{kDa}$ was observed in rats, and a similarly sized band of $\sim 75 \mathrm{kDa}$ was observed in Xenopus. $B, C$, Immunolabeling of stage 35/36 Xenopus transverse sections with the ADAM10 antibody shows labeling of cells in the diencephalon $(B)$ and in the RGC layer $(C)$. Note that there is no immunoreactivity in the neuropil or the optic nerve. $N p$, Neuropil; $D i$, diencephalon; $P E$, pigment epithelium; $R G C L$, RGC layer; $L$, lens; $D$, dorsal; $V$, ventral. Scale bars, $50 \mu \mathrm{m}$.

the target boundary failed to enter the target and instead turned and grew along the anterior tectal border. At the higher doses of metalloprotease inhibitors, RGC axons were also impaired in their outgrowth. These in vivo data strongly support a role for metalloproteases in axon guidance and extension in the developing vertebrate visual system.

Presumably, as suggested from culture experiments (Galko and Tessier-Lavigne, 2000; Hattori et al., 2000), metalloproteases regulate the responsiveness of $\mathrm{RGC}$ axons to guidance cues by cleavage of the ectodomains of specific ligands or their receptors. In our study, the metalloprotease inhibitors would have access to both the axons and the neuroepithelium through which they travel. As such, metalloproteases may function in either the substrate or the axons, or perhaps both, to ensure proper guidance. Our data cannot differentiate between the two possibilities. XKUZ and several other metalloproteases are expressed in the Xenopus diencephalon around the time RGC axons are extending through the brain (Alfandari et al., 1997; Pan and Rubin, 1997; Cai et al., 1998; Damjanovski et al., 2000). Conversely, embryonic vertebrate RGCs and their axons express metalloproteases (Sheffield and Graff, 1991; Sheffield et al., 1994; Canete Soler et al., 1995). This is also true of many vertebrate growth cones extending in vitro (Nordstrom et al., 1995; Zuo et al., 1998; ChambautGuerin et al., 2000; Hayashita-Kinoh et al., 2001). However, metalloprotease inhibitors had no obvious effect on the morphology of cultured Xenopus RGC growth cones. Although this would argue that metalloproteases do not operate within the growth cone, it is likely that the guidance receptors that would normally be cleaved by the metalloproteases do not function when axons are growing over a simplified laminin substrate. Indeed, metalloprotease inhibitors do affect the morphology of chick RGC growth cones growing on a more complicated tectal membrane substrate (Schlosshauer et al., 1990). The metalloprotease inhibitors also had no effect on the general patterning of the neuroepithelium, but one might expect that they would affect only specific axon guidance molecules, such as we observed with DCC. Future molecular experiments manipulating the function of metalloproteases specifically in RGC axons, or the diencephalon, could address the issue of the site of metalloprotease activity. Despite the plethora of metalloproteases, the fact that axon guidance defects may be associated with individual metalloprotease mutants in Drosophila and mice indicates that such an approach may prove fruitful (Leighton et al., 2001; Schimmelpfeng et al., 2001).

Several interesting candidate molecules might underlie the axon guidance defects we observed with the metalloprotease inhibitors. Three recognized guidance molecules for RGC axons are known to be cleaved by metalloproteases: Fibroblast growth factor receptors (FGFRs) (Levi et al., 1996), DCC (Galko and Tessier-Lavigne, 2000), and ephrins (Hattori et al., 2000). All three are expressed in the developing Xenopus visual system and function in RGC axon guidance. Ephrins have been shown to function in the topographic mapping of vertebrate RGC axon projections (O'Leary and Wilkinson, 1999) and axon divergence at the Xenopus optic chiasm (Nakagawa et al., 2000). However, no evidence suggests that they direct the proper trajectories of the axons in the diencephalon. Interestingly, treatment of posterior and anterior tectal membranes with metalloprotease inhibitors had no effect on the normal repulsive activity of posterior membranes for chick RGC axons (Schlosshauer et al., 1990), despite the observation that metalloprotease inhibitors prolonged ephrin interactions with their ephrin receptors in mouse embryonic neuronal cultures (Hattori et al., 2000).

The regulation of DCC signaling by metalloproteases has, in contrast, been demonstrated both in vitro and in vivo. For example, in Caenorhabditis elegans, genetic interactions were observed between mutants for MIG-17, a member of the ADAM family, and the worm Netrin ortholog UNC-6 (Nishiwaki et al., 2000). In addition, Netrin-1-stimulated neurite outgrowth from rat embryonic spinal cord explants was potentiated by metalloprotease inhibitors (Galko and Tessier-Lavigne, 2000). This effect was likely attributable to greater numbers of intact DCC receptors, because the metalloprotease inhibitors blocked DCC ectodomain shedding in DCC-transfected Chinese hamster ovary cells. Interestingly, DCC is expressed by both Xenopus RGC axons and the diencephalic neuroepithelium, suggesting that in our experiments the inhibitors could be acting on either population of receptors (de la Torre et al., 1997). Although DCC is known to function in prompting RGC axons to leave the eye and in guidance at the optic chiasm (Deiner et al., 1997; Deiner and Sretavan, 1999), its role in guiding axons at later points in the optic pathway is unknown. The expression of DCC mRNA in neuroepithelial cells in the middiencephalon and the border of the optic tectum (de la Torre et al., 1997) raises the possibility that normal metalloprotease-dependent regulation of DCC function is required in the substrate to direct RGC axons properly. Consistent with this, we found that after treatment with metalloprotease inhibitors, the brain neuropil was more brightly labeled with an antibody raised against the ectodomain of DCC.

Finally, we have shown previously that inhibiting RGC growth cone FGFRs caused the axons to avoid their tectal target in a manner similar to that observed with the metalloprotease inhibitors (McFarlane et al., 1996). Previous studies have shown that MMP-2 can cleave the extracellular portion of the FGFR (Levi et al., 1996). The neurotrophin tyrosine kinase receptor TrkA can be similarly processed by metalloproteases (Diaz-Rodriguez et al., 1999). The cleavage results in the generation of cell-bound receptor fragments whose intracellular domain is constitutively 
Figure 8. Metalloprotease inhibitor treatment does not grossly affect growth cone morphology or the patterning or morphology of the neuroepithelium. $A$, $B$, Control $(A)$ or $5 \mu \mathrm{M}$ GM6001-treated $(B)$ growth cones in culture. $C-H$, Cross sections through the diencephalon/midbrain regions of stage 40 embryos exposed at stage $33 / 34$ to control $(0.4 \%$ DMSO) or $10 \mu \mathrm{M}$ GM6001 bathing solutions. In all panels, the exposed side of the brain is on the left, and the unexposed side is on the right. Note that the left eye is removed during the exposure. Sections were immunolabeled with markers of the neuroepithelium. $C, D$, $\mathrm{Zn}$-12 immunolabeling of control brains $(C)$ and brains exposed to GM6001 (D). $E, \beta$-tubulin immunoreactivity of a GM6001-treated brain. $F$, Islet-1 immunolabeling of ventrally located neurons (arrows) in a GM6001-treated brain showing that dorsoventral polarity is maintained. $G, H$, Immunolabeling of control $(G)$ and GM6001-treated $(H)$ brains with a rabbit polyclonal GABA antibody. GABAergic neurons found in the mid-diencephalon are present in both control and experimental brains. $R$, Retina; $D i$, diencephalon; $V e$, ventricle; $M b$, midbrain; $D$, dorsal; $V$, ventral. Scale bar: (in $H$ ) $A, B, 10 \mu$ m; $C-H, 50 \mu \mathrm{m}$.

Figure 9. Defects in RGC axon target recognition caused by the late application of GM6001. Brains were exposed at stage $37 / 38$ to either a control solution $(A)$ or $5 \mu \mathrm{M}$ GM6001 $(B-E)$, and optic projections were HRP-labeled at stage 40. Target-recognition defects are evident in the GM6001-treated brains. Axons grow dorsally along the anterior border of the optic tectum and then cross over the dorsal midline into the contralateral brain $(D) . E$ is a higher-power view of the boxed area in $C$. Scale bars: $C$ (for $A-C$ ), $D, 50 \mu \mathrm{m} ; E, 25 \mu \mathrm{m}$.
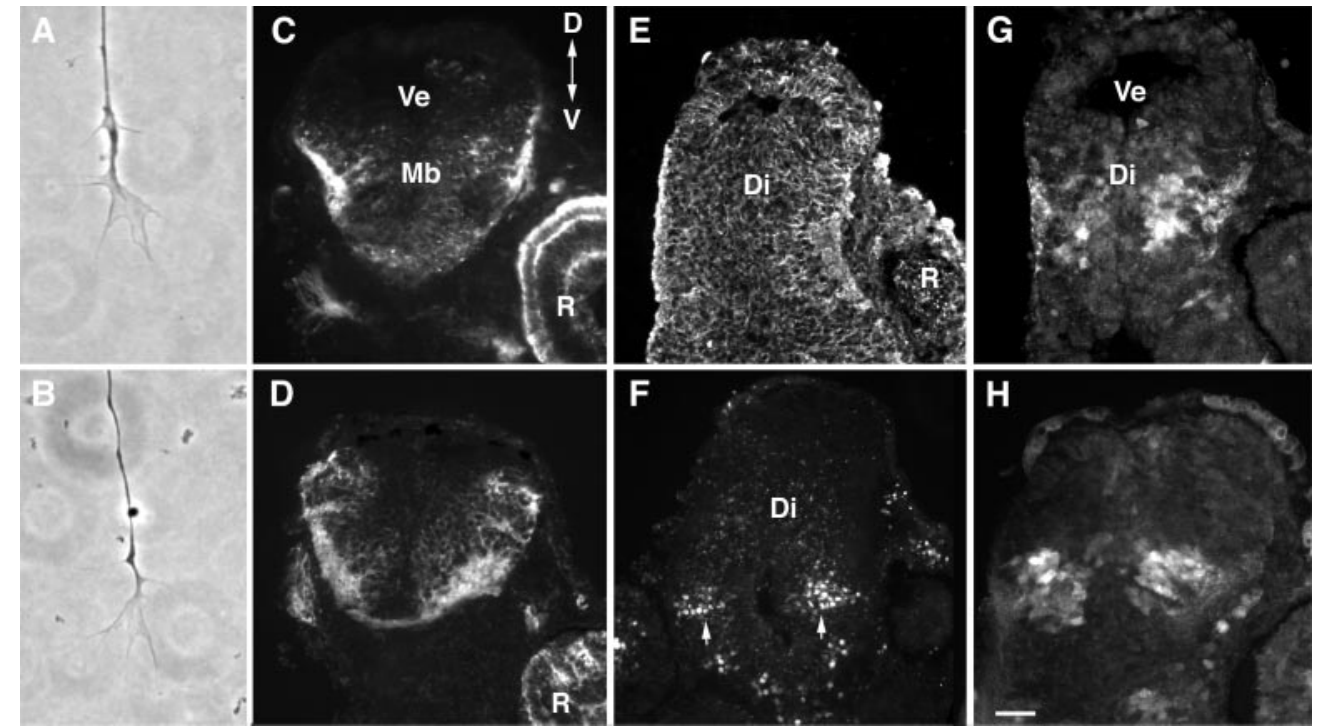
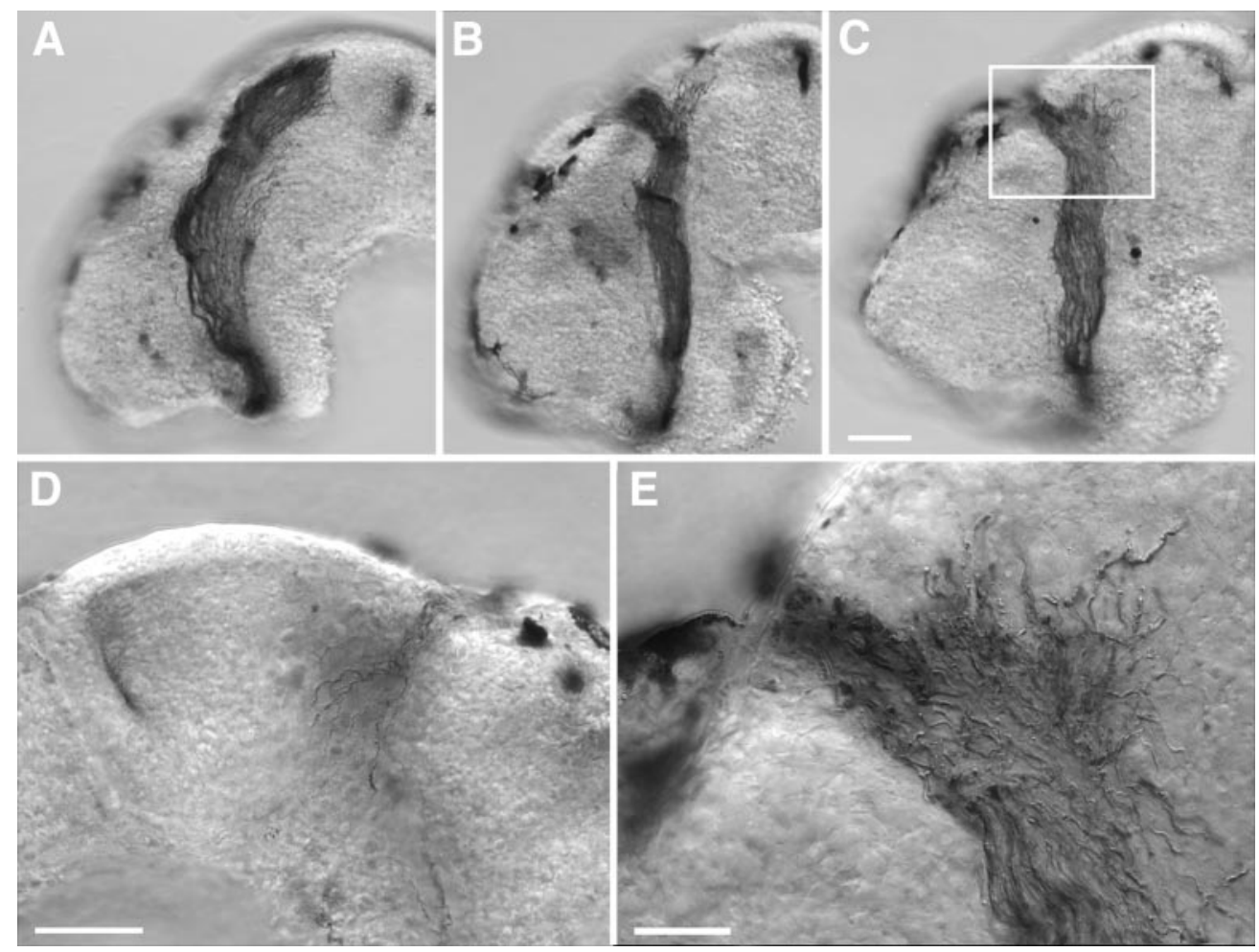

tyrosine phosphorylated, and presumably leads to signal transduction downstream of the receptor. Possibly, a similar activation mechanism could occur with the ectodomain of the FGFR, also a receptor tyrosine kinase. If so, blocking metalloprotease activity and FGFR ectodomain shedding would produce targetrecognition defects similar to inhibiting FGFR function with a dominant negative receptor (McFarlane et al., 1996). Although Xenopus MMP-2 has been identified, whether it is expressed at the right time to influence RGC FGFR signaling has not yet been determined (Jung et al., 2002).

The fact that the higher metalloprotease inhibitor doses im- paired RGC axon growth is not surprising given culture data showing that metalloprotease activity is required for axon extension. For instance, metalloprotease function promotes the extension of regenerating embryonic chick dorsal root ganglion neurites (Zuo et al., 1998), and in Drosophila kuz mutants axons stall (Fambrough et al., 1996). In addition, when rat pheochromocytoma cells that constitutively expressed stromelysin-1 antisense mRNA were induced to differentiate, their ability to extend neurites was significantly impaired (Nordstrom et al., 1995). Metalloprotease-dependent promotion of extension could result from the ligand-independent activation of growth factor receptor 
signaling after cleavage (Diaz-Rodriguez et al., 1999); by the elimination or exposure of substrate-localized growth-inhibitory or growth-stimulatory proteins, respectively (Giannelli et al., 1997; Zuo et al., 1998; Belien et al., 1999); or possibly, in the case of ADAM proteins, by a cell-adhesion-dependent mechanism (Fambrough et al., 1996). What is interesting is that in many instances we found defects in RGC axon guidance with no accompanying defect in axon extension. One possible explanation for these results is that at higher concentrations GM6001 and BB-94 affect metalloprotease-independent targets that are required for extension. For several reasons, we propose instead that different metalloproteases function in modulating axon extension and guidance, with those regulating axon trajectories being more sensitive to the inhibitors used in this study. First, the concentrations we used in our study are those commonly reported for in vitro studies (Parvathy et al., 1998; Alexander et al., 2001; Karsdal et al., 2001; Nath et al., 2001; Jung et al., 2002). Second, it is likely that with our in vivo preparation neuroepithelial cells and RGC axons actually encounter considerably lower concentrations than those applied to the bath. Finally, a number of culture studies have reported effects with one of the tissue inhibitors of metalloproteases that are similar to those seen for either GM6001 or BB-94 at the higher concentrations used in our study (Hargreaves et al., 1998; Nabeshima et al., 2000; Alexander et al., 2001; Nath et al., 2001; Ala-Aho et al., 2002). The fact that two chemically distinct inhibitor types produce identical phenotypes argues that the hydroxamate inhibitors are specifically acting on metalloproteases.

Intracellular cyclic nucleotides and calcium levels are important in determining how a growth cone responds to a specific guidance cue (McFarlane, 2000). Clearly, proteolytic enzymes produced either by cells in the substrate or the growing axons themselves provide an additional level of regulation for the action of guidance cues. The variety of metalloproteases expressed in the developing brain suggests that the regulation could be quite complex and sophisticated. Future studies will need to determine which metalloproteases are important and what subset of guidance molecules they regulate.

\section{REFERENCES}

Agapova OA, Ricard CS, Salvador-Silva M, Hernandez MR (2001) Expression of matrix metalloproteinases and tissue inhibitors of metalloproteinases in human optic nerve head astrocytes. Glia 33:205-216.

Ala-Aho R, Johansson N, Baker AH, Kahari VM (2002) Expression of collagenase-3 (MMP-13) enhances invasion of human fibrosarcoma HT-1080 cells. Int J Cancer 97:283-289.

Alexander CM, Selvarajan S, Mudgett J, Werb Z (2001) Stromelysin-1 regulates adipogenesis during mammary gland involution. J Cell Biol 152:693-703.

Alfandari D, Wolfsberg TG, White JM, DeSimone DW (1997) ADAM 13: a novel ADAM expressed in somitic mesoderm and neural crest cells during Xenopus laevis development. Dev Biol 182:314-330.

Alfandari D, Cousin H, Gaultier A, Smith K, White JM, Darribere T, DeSimone DW (2001) Xenopus ADAM 13 is a metalloprotease required for cranial neural crest-cell migration. Curr Biol 11:918-930.

Belien AT, Paganetti PA, Schwab ME (1999) Membrane-type 1 matrix metalloprotease (MT1-MMP) enables invasive migration of glioma cells in central nervous system white matter. J Cell Biol 144:373-384.

Brown PD (1998) Matrix metalloproteinase inhibitors. Breast Cancer Res Treat 52:125-136.

Cai H, Kratzschmar J, Alfandari D, Hunnicutt G, Blobel CP (1998) Neural crest-specific and general expression of distinct metalloproteasedisintegrins in early Xenopus laevis development. Dev Biol 204:508-524.

Canete Soler R, Gui YH, Linask KK, Muschel RJ (1995) MMP-9 (gelatinase B) mRNA is expressed during mouse neurogenesis and may be associated with vascularization. Brain Res Dev Brain Res 88:37-52.

Carinato ME, Walter BE, Henry JJ (2000) Xenopus laevis gelatinase B (Xmmp-9): development, regeneration, and wound healing. Dev Dyn 217:377-387.

Chambaut-Guerin AM, Herigault S, Rouet-Benzineb P, Rouher C, Lafuma C (2000) Induction of matrix metalloproteinase MMP-9 (92-
kDa gelatinase) by retinoic acid in human neuroblastoma SKNBE cells: relevance to neuronal differentiation. J Neurochem 74:508-517.

Chien CB, Harris WA (1994) Axonal guidance from retina to tectum in embryonic Xenopus. Curr Top Dev Biol 29:135-169.

Chien CB, Rosenthal DE, Harris WA, Holt CE (1993) Navigational errors made by growth cones without filopodia in the embryonic $\mathrm{Xe}$ nopus brain. Neuron 11:237-251.

Cornel E, Holt C (1992) Precocious pathfinding: retinal axons can navigate in an axonless brain. Neuron 9:1001-1011.

Damjanovski S, Puzianowska-Kuznicka M, Ishuzuya-Oka A, Shi YB (2000) Differential regulation of three thyroid hormone-responsive matrix metalloproteinase genes implicates distinct functions during frog embryogenesis. FASEB J 14:503-510. arsid16667055

Deiner MS, Sretavan DW (1999) Altered midline axon pathways and ectopic neurons in the developing hypothalamus of netrin-1- and DCCdeficient mice. J Neurosci 19:9900-9912. arsid16667055 arsid16667055

Deiner MS, Kennedy TE, Fazeli A, Serafini T, Tessier-Lavigne M, Sretavan DW (1997) Netrin-1 and DCC mediate axon guidance locally at the optic disc: loss of function leads to optic nerve hypoplasia. Neuron 19:575-589. arsid16667055

de la Torre JR, Hopker VH, Ming GL, Poo MM, Tessier-Lavigne M, Hemmati-Brivanlou A, Holt CE (1997) Turning of retinal growth cones in a netrin- 1 gradient mediated by the netrin receptor DCC. Neuron 19:1211-1224.

Diaz-Rodriguez E, Cabrera N, Esparis-Ogando A, Montero JC, Pandiella A (1999) Cleavage of the TrkA neurotrophin receptor by multiple metalloproteases generates signalling-competent truncated forms. Eur J Neurosci 11:1421-1430.

Ericson J, Muhr J, Jessell TM, Edlund T (1995) Sonic hedgehog: a common signal for ventral patterning along the rostrocaudal axis of the neural tube. Int J Dev Biol 39:809-816.

Fambrough D, Pan D, Rubin GM, Goodman CS (1996) The cell surface metalloprotease/disintegrin Kuzbanian is required for axonal extension in Drosophila. Proc Natl Acad Sci USA 93:13233-13238.

Ferguson SC, McFarlane S (2002) GABA and development of the $\mathrm{Xe}$ nopus optic projection. J Neurobiol 51:272-284.

Galko MJ, Tessier-Lavigne M (2000) Function of an axonal chemoattractant modulated by metalloprotease activity. Science 289:1365-1367.

Giannelli G, Falk-Marzillier J, Schiraldi O, Stetler-Stevenson WG, Quaranta V (1997) Induction of cell migration by matrix metalloprotease-2 cleavage of laminin-5. Science 277:225-228.

Goodman SA, Albano R, Wardle FC, Matthews G, Tannahill D, Dale L (1998) BMP1-related metalloproteinases promote the development of ventral mesoderm in early Xenopus embryos. Dev Biol 195:144-157.

Hargreaves PG, Wang F, Antcliff J, Murphy G, Lawry J, Russell RG, Croucher PI (1998) Human myeloma cells shed the interleukin-6 receptor: inhibition by tissue inhibitor of metalloproteinase- 3 and a hydroxamate-based metalloproteinase inhibitor. $\mathrm{Br} \mathrm{J}$ Haematol 101:694-702.

Harris WA, Messersmith SL (1992) Two cellular inductions involved in photoreceptor determination in the Xenopus retina. Neuron 9:357-372

Hattori M, Osterfield M, Flanagan JG (2000) Regulated cleavage of a contact-mediated axon repellent. Science 289:1360-1365.

Hayashita-Kinoh H, Kinoh H, Okada A, Komori K, Itoh Y, Chiba T, Kajita M, Yana I, Seiki M (2001) Membrane-type 5 matrix metalloproteinase is expressed in differentiated neurons and regulates axonal growth. Cell Growth Differ 12:573-580.

Jung JC, Leco KJ, Edwards DR, Fini ME (2002) Matrix metalloproteinases mediate the dismantling of mesenchymal structures in the tadpole tail during thyroid hormone-induced tail resorption. Dev Dyn 223:402-413.

Karsdal MA, Fjording MS, Foged NT, Delaisse JM, Lochter A (2001) Transforming growth factor- $\beta$-induced osteoblast elongation regulates osteoclastic bone resorption through a p38 mitogen-activated protein kinase- and matrix metalloproteinase-dependent pathway. J Biol Chem 276:39350-39358.

Leighton PA, Mitchell KJ, Goodrich LV, Lu X, Pinson K, Scherz P, Skarnes WC, Tessier-Lavigne M (2001) Defining brain wiring patterns and mechanisms through gene trapping in mice. Nature 410:174-179.

Levi E, Fridman R, Miao HQ, Ma YS, Yayon A, Vlodavsky I (1996) Matrix metalloproteinase 2 releases active soluble ectodomain of fibroblast growth factor receptor 1. Proc Natl Acad Sci USA 93:7069-7074

Machida CM, Rodland KD, Matrisian L, Magun BE, Ciment G (1989) NGF induction of the gene encoding the protease transin accompanies neuronal differentiation in PC12 cells. Neuron 2:1587-1596.

McFarlane S (2000) Attraction vs. repulsion: the growth cone decides. Biochem Cell Biol 78:563-568.

McFarlane S, Pollock NS (2000) A role for voltage-gated potassium channels in the outgrowth of retinal axons in the developing visual system. J Neurosci 20:1020-1029.

McFarlane S, McNeill L, Holt CE (1995) FGF signaling and target recognition in the developing Xenopus visual system. Neuron 15:1017-1028.

McFarlane S, Cornel E, Amaya E, Holt CE (1996) Inhibition of FGF 
receptor activity in retinal ganglion cell axons causes errors in target recognition. Neuron 17:245-254.

Metcalfe WK, Myers PZ, Trevarrow B, Bass MB, Kimmel CB (1990) Primary neurons that express the L $2 / \mathrm{HNK}-1$ carbohydrate during early development in the zebrafish. Development 110:491-504.

Nabeshima K, Inoue T, Shimao Y, Okada Y, Itoh Y, Seiki M, Koono M (2000) Front-cell-specific expression of membrane-type 1 matrix metalloproteinase and gelatinase A during cohort migration of colon carcinoma cells induced by hepatocyte growth factor/scatter factor. Cancer Res 60:3364-3369.

Nakagawa S, Brennan C, Johnson KG, Shewan D, Harris WA, Holt CE (2000) Ephrin-B regulates the ipsilateral routing of retinal axons at the optic chiasm. Neuron 25:599-610.

Nath D, Williamson NJ, Jarvis R, Murphy G (2001) Shedding of c-Met is regulated by crosstalk between a G-protein coupled receptor and the EGF receptor and is mediated by a TIMP-3 sensitive metalloproteinase. J Cell Sci 114:1213-1220.

Nieuwkoop PD, Faber J (1994) Normal table of Xenopus laevis. New York: Garland.

Nishiwaki K, Hisamoto N, Matsumoto K (2000) A metalloprotease disintegrin that controls cell migration in Caenorhabditis elegans. Science 288:2205-2208.

Nordstrom LA, Lochner J, Yeung W, Ciment G (1995) The metalloproteinase stromelysin-1 (transin) mediates PC12 cell growth cone invasiveness through basal laminae. Mol Cell Neurosci 6:56-68.

O'Leary DD, Wilkinson DG (1999). Eph receptors and ephrins in neural development. Curr Opin Neurobiol 9:65-73.

Pan D, Rubin GM (1997) Kuzbanian controls proteolytic processing of Notch and mediates lateral inhibition during Drosophila and vertebrate neurogenesis. Cell 90:271-280.

Parvathy S, Hussain I, Karran EH, Turner AJ, Hooper NM (1998) Alzheimer's amyloid precursor protein $\alpha$-secretase is inhibited by hydroxamic acid-based zinc metalloprotease inhibitors: similarities to the angiotensin converting enzyme secretase. Biochemistry 37:1680-1685.

Piccolo S, Agius E, Lu B, Goodman S, Dale L, De Robertis EM (1997) Cleavage of chordin by xolloid metalloprotease suggests a role for proteolytic processing in the regulation of Spemann organizer activity. Cell 91:407-416.
Pittman RN (1985) Release of plasminogen activator and a calciumdependent metalloprotease from cultured sympathetic and sensory neurons. Dev Biol 110:91-101.

Roberts A, Dale N, Ottersen OP, Storm-Mathisen J (1987) The early development of neurons with GABA immunoreactivity in the CNS of Xenopus laevis embryos. J Comp Neurol 261:435-449.

Schimmelpfeng K, Gogel S, Klambt C (2001) The function of leak and kuzbanian during growth cone and cell migration. Mech Dev 106:25-36.

Schlondorff J, Blobel CP (1999) Metalloprotease-disintegrins: modular proteins capable of promoting cell-cell interactions and triggering signals by protein-ectodomain shedding. J Cell Sci 112:3603-3617.

Schlosshauer B, Walter J, Bonhoeffer F (1990) Is guidance of chick retinal axons in vitro influenced by proteases? Neurosci Lett 113:333-338.

Sheffield JB, Graff D (1991) Extracellular proteases in developing chick neural retina. Exp Eye Res 52:733-741.

Sheffield JB, Krasnopolsky V, Dehlinger E (1994) Inhibition of retinal growth cone activity by specific metalloproteinase inhibitors in vitro. Dev Dyn 200:79-88.

Sive HL, Grainger RM, Harland RM (2000) Early development of $X e$ nopus laevis: a laboratory manual. Cold Spring Harbor, NY: Cold Spring Harbor Laboratory.

Vaillant C, Didier-Bazes M, Hutter A, Belin MF, Thomasset N (1999) Spatiotemporal expression patterns of metalloproteinases and their inhibitors in the postnatal developing rat cerebellum. J Neurosci 19:4994-5004.

Yang M, Murray MT, Kurkinen M (1997) A novel matrix metalloproteinase gene (XMMP) encoding vitronectin-like motifs is transiently expressed in Xenopus laevis early embryo development. J Biol Chem 272:13527-13533.

Yong VW, Power C, Forsyth P, Edwards DR (2001) Metalloproteinases in biology and pathology of the nervous system. Nat Rev Neurosci 2:502-511.

Zuo J, Ferguson TA, Hernandez YJ, Stetler-Stevenson WG, Muir D (1998) Neuronal matrix metalloproteinase-2 degrades and inactivates a neurite-inhibiting chondroitin sulfate proteoglycan. J Neurosci 18 : 5203-5211. 